\title{
A Proposal to Design of an Integrated System for Analysis of Structural Performance and Environmental Impact Assessments
}

\author{
Ali Jamshidi", Kiyofumi Kurumisawa, Toyoharu Nawa \\ Faculty of Engineering, Hokkaido University, Japan
}

Copyright (C) 2015 by authors, all rights reserved. Authors agree that this article remains permanently open access under the terms of the Creative Commons Attribution License 4.0 International License

\begin{abstract}
This study proposes a simple methodology that enables concrete infrastructure asset (CIA) designers to analyze structural performance and environmental loads, in terms of greenhouse gas emissions. In this respect, mortar samples containing a type of industrial by-product material, namely fly ash, were prepared. The analysis covers material processing, concrete production, and transportation. A methodology to compare sustainability of CIAs based on the Carbon footprint criteria was developed based on the mechanical performance and environmental loadings according to the conditioning procedures. The results clearly showed the efficient performance of the proposal method in green design of CIAs.
\end{abstract}

Keywords Sustainable Construction, Cleaner Design, Green Pavement, Concrete Block Pavement

\section{Introduction}

A nation's economy is strongly linked to its ability to feed and shelter citizens and defended itself. Such performances depend on the infrastructure assets designed by engineers. Significant role of infrastructure asset, as foundation of society's wealth, is often neglected. The infrastructure asset performance affects productivity, emission, public health issue. In addition, a nation's potentials in natural and manmade disasters are measured based on the available infrastructure assets that classified in seven main groups: (1) Transportation; (2) Water and waste water; (3) Waste management; (4) Energy production and distribution; (5) Buildings; (6) Recreation facilities; (7) Communications.

As shown, transportation is one of the important assets and or CIA that can be considered as cornerstone of a sustainable economic growth. Transportation infrastructure asset consists four main components as follow: (1) Pavements; (2) Drainage systems; (3) Marking, signs, and signals; and (4) Navigation and control devises.

The pavements are the most important components of the transportation infrastructure assets. They can be considered as long-live assets that provides transportation of passengers and goods in an efficient and safe mode. In fact, the pavements are one of expensive assets that significantly depend on the non-renewable natural resources, aggregate and carbon-based energy carrier. There is a harsh pressure on the aggregate resources due to the fast development of the infrastructure assets. As an example, China flatted 700 mountains to build a city in 2012 [1]. Although crude oil price have been decreased recently, it should not affect the concept of green infrastructure asset. Therefore, it is necessary to find alternative materials, sustainable technologies that ease the pressure on the non-renewable natural resources for the pavement construction. Meanwhile, there is a wide range of pavement material alternatives that will give satisfactory service. The choice of pavement type and the alternative material is often made subjectively. It means that selection is usually a matter of the engineering skill, judgment and experience. Also, characterization of sustainability is important in design and construction of various pavement types. Technically speaking, there is no difference between a traditional and sustainable pavement structural design with and without energy saving and GHG emissions taken into account. The difference lies in the amount of energy saving due to use of various alternative materials and sustainable technology. To address this need, fuel requirement and GHG emissions are measured and compared for various concrete block pavements as selected CIA in this study. Also, an integrated system is defined as a tool for the sustainable/structural evaluation and comparison of various pavement type.

\section{Material and Methods}

By-product Material

By-product used in this study was fly ash (FA). It is a 
by-product material of coal-fired electric power plants. It can be used as an alternative for cement in the concrete pavements. The physical and mineralogical, and chemical characteristics of FA affect the concrete product properties. $15 \%$ (moderate level) and 30\% (high level) of cement was replaced with FA for cement treated base used for the pavement system.

\section{Asphalt Concrete Base}

Type of asphalt binder used for construction of asphalt slab was PG 64. Tables 1 and 2 show the binder properties and aggregate gradation, respectively. Asphalt mixture was produced at $130^{\circ} \mathrm{C}$.

Table 1. Rheological properties of asphalt binders

\begin{tabular}{|c|c|c|}
\hline Aging State & Material Property & Value \\
\hline $\begin{array}{c}\text { Unaged } \\
\text { (original state) }\end{array}$ & Viscosity at $135^{\circ} \mathrm{C}(\mathrm{mPa} . \mathrm{s})$ & 465.0 \\
\cline { 2 - 3 } & $\mathrm{G}^{*} / \sin (\delta)$ at $64^{\circ} \mathrm{C}(\mathrm{kPa})$ & 1.23 \\
\hline Short-term-aged & $\mathrm{G}^{*} / \sin (\delta)$ at $64^{\circ} \mathrm{C}(\mathrm{kPa})$ & 2.68 \\
\hline Long-term-aged & $\mathrm{G}^{*} \sin (\delta)$ at $25^{\circ} \mathrm{C}(\mathrm{kPa})$ & 2959 \\
\hline
\end{tabular}

Table 2. Aggregate gradation for the asphalt concrete slab

\begin{tabular}{|c|c|}
\hline Aggregate size & Percent Passing \\
\hline 100 & 100 \\
\hline 14 & $90-100$ \\
\hline 10 & $67-86$ \\
\hline 5 & $50-62$ \\
\hline 3.35 & $40-54$ \\
\hline 1.18 & $18-34$ \\
\hline 0.425 & $12-24$ \\
\hline 0.15 & $6-12$ \\
\hline 0.75 & $4-8$ \\
\hline
\end{tabular}

\section{Cement Concrete Base}

Cement mortar (mixture of cement paste and sand) was chosen for base layer. Table 3 shows the property of the control slab (without FA) and slabs containing various FA percentages that were determined by the elastic modulus test.

Table 3. Engineering properties of the mortar samples

\begin{tabular}{|c|c|c|c|}
\hline \multirow{2}{*}{ Mixture } & Property & Value & Unit \\
\cline { 2 - 3 } & Water binder ratio (W/B) & 40 & $\%$ \\
\cline { 2 - 3 } & Curing Temperature & 22 & ${ }^{\circ} \mathrm{C}$ \\
\hline \multirow{2}{*}{ Control } & & 22.75 & \multirow{2}{*}{$\mathrm{GPa}$} \\
\hline $15 \% \mathrm{FA}$ & Elastic modulus & 20.16 & \\
$30 \% \mathrm{FA}$ & & 15.86 & \\
\cline { 3 - 4 } & & & \\
\hline
\end{tabular}

\section{Traffic Loading}

The pavements were designed for two applications: (1) highways; (2) ports. Traffic loading of the highway pavement was $1,000,000$ equivalent standard axle load (ESAL) 8.2 ton $(80 \mathrm{kN}$ or $18 \mathrm{kips})$. For the highway pavement, a $10 \mathrm{~km}$ two directional highway was assumed that each line has three lanes or carriage way (width is 3.48 m). Figure 1(a) illustrates the schematically assumed highway pavement in this study.

Design vehicle for the pavement port is a straddle carrier with two axles with twin wheel (Figure $1\left(b_{1}\right)$ ). The tire pressure is $0.9 \mathrm{MPa}$ with $1,000,000$ passes. The effects of the vehicle wander were also included in the structural design. The length of the track way or aisle in the port was $10 \mathrm{~m}$ (Figure 1( $\left.\mathrm{b}_{2}\right)$ ). The pavement is design for the laden straddle carrier with $50 \%$ standard container $12 \mathrm{~m}(40 \mathrm{ft})$ and $6 \mathrm{~m}(20 \mathrm{ft})$, i.e., $50 \%$ container $12 \mathrm{~m}$ and $50 \%$ container $6 \mathrm{~m}$.

Four prototypes of pavement section were chose for evaluation (Table 4). The paving layers is concrete block with various thicknesses $(80,100$, and $120 \mathrm{~mm})$. The elastic modulus of the block paver is 2,500 MPa. The block shape and laying pattern were rectangular and herringbone, respectively.

Table 4. Various pavement section

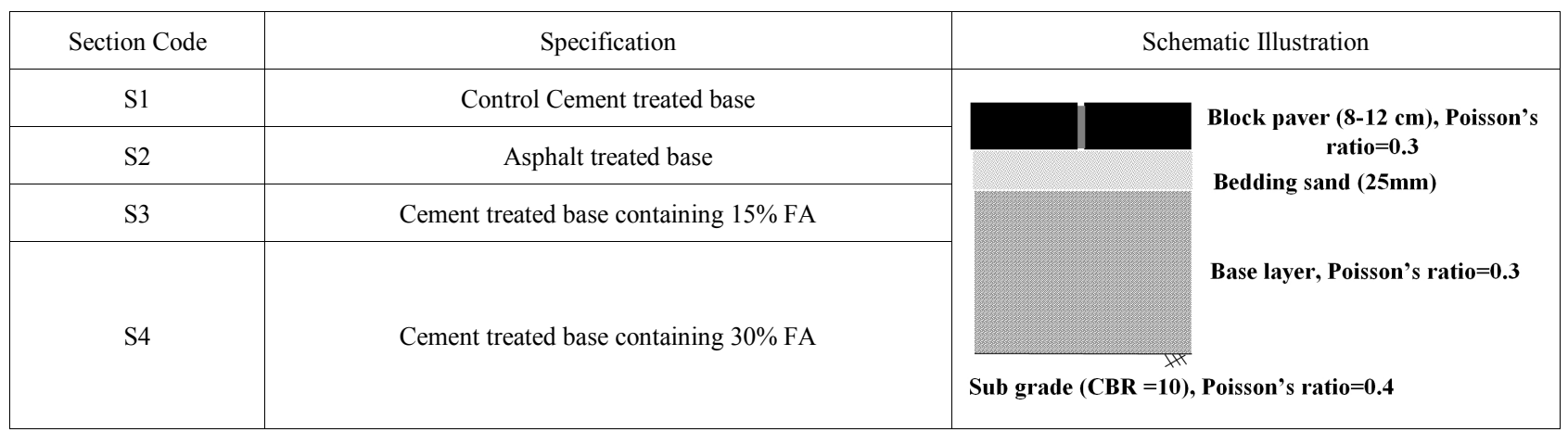


Two directional highway with 2 lines

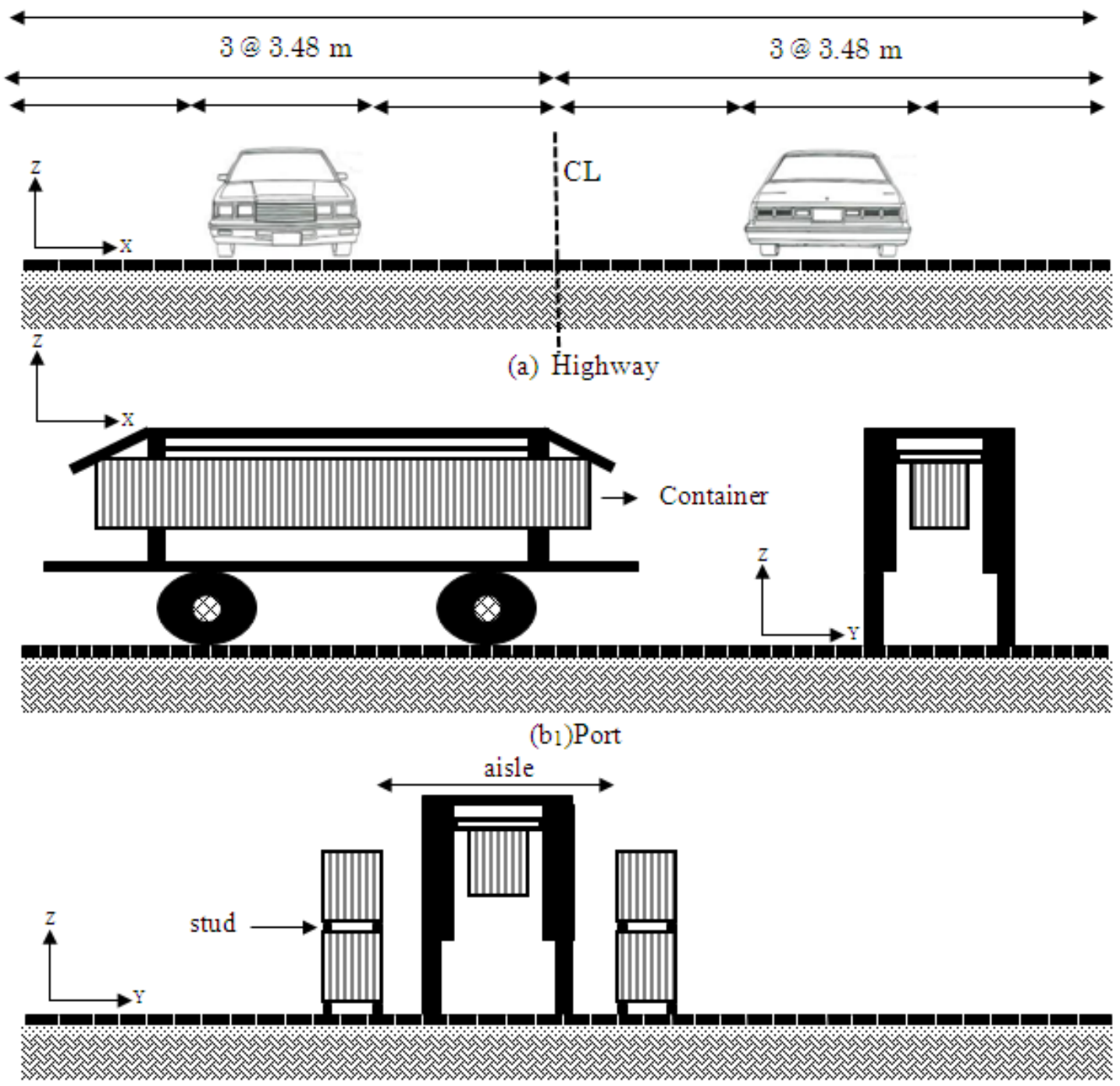

(b2) the aisle in the port

Figure 1. Schematic illustration of the pavement section

Environmental Impact Assessment

The energy required to produce the cement, asphalt, and aggregate production was converted to the required amount of natural gas as an industrial fuel type. Amount of energy consumption for raw material production, asphalt and concrete placement were computed according to Zapata and Gombatese [2]. Conversion coefficient used for the natural gas was 0.02610824 cubic meter per mega Joule [3] and the conversion factors for $\mathrm{GHG}$ in terms of $\mathrm{CO}_{2}$, is $2.023 \mathrm{~kg}$ $\mathrm{CO}_{2} \mathrm{e} /$ unit [4].

\section{Result and Discussion}

Figures 2 shows the required base thickness for the various pavement sections. Figure 2(a) clearly shows that required thickness for the asphalt slab (S2) is lower than those of concrete slab. As a result, the low thickness of the asphalt base also requires less raw material, while Figure 2 (b) shows that $\mathrm{S} 2$ has the maximum thickness. Figure 2(a) also indicates that the thickness for S1, S3 and S4 are the same (minimum thickness according to ICPI [5], indicating equal structural performance of concrete bases for the highway pavement, but the S1, S2, S3 require different base thickness for the port pavement. Figure 2 (a) also indicates that the block thickness has no effect on the base thickness design. In contrast, Figure 2 (b) shows the results of indicate the base thickness decreases when block thickness increases. Moreover, Figure 2 (a) presents that incorporation of FA has no negative effect on the structural performance of the pavement system; However, Figure 2(b) shows that higher thickness is needed for the base containing FA. Therefore, structural response of pavement material can be attributed to the pavement application. In the port, the type and mode of vehicular loadings are different from the highways. 


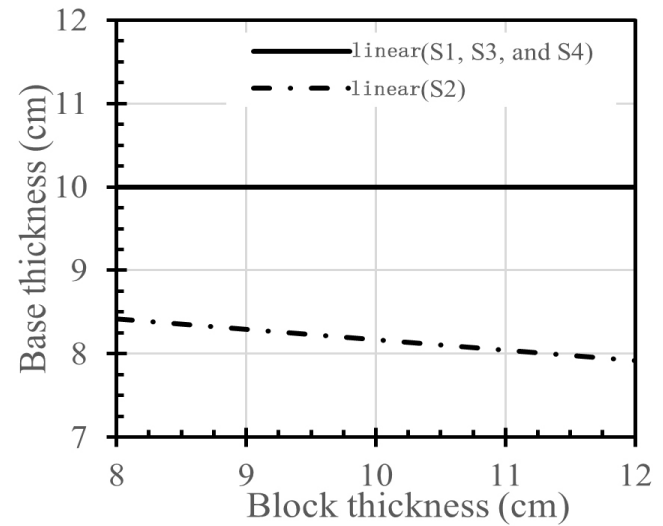

(a) highway

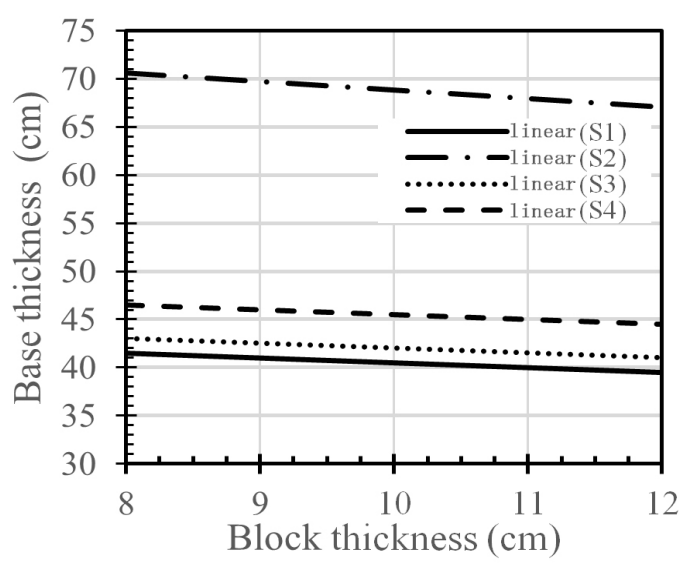

(b) port

Figure 2. Required base thickness for the various concrete block pavement sections.

Figure 3 shows the amount of fuel consumption for the highway and port pavement constructions. Although less materials are consumed for S2 for the highway pavements due to lower thickness, fuel requirement is much higher than the other pavement sections for the highway (Figure 3 (a)). For example, S2 with block paver $80 \mathrm{~cm}$ requires $5.6 \times 10^{7} \mathrm{~m}^{3}$ natural gas, while $\mathrm{S} 1$ as a control section requires $2.8 \times 10^{6} \mathrm{~m}^{3}$ with the same block thickness, which is
$5.3 \times 10^{7} \mathrm{~m}^{3}$ lower fuel. Moreover, the fuel requirement significant decreases when FA is used as alternative materials (Figure 3(b)). As an instance, S4 with $10 \mathrm{~cm}$ block requires $1.94 \times 10^{6} \mathrm{~m}^{3}$, while the corresponding value is $2.86 \times 10^{6} \mathrm{~m}^{3}$ for $\mathrm{S} 1$. As a consequence, construction of $\mathrm{S} 3$ and $\mathrm{S} 4$ needs lower energy as compared with $\mathrm{S} 1$ and $\mathrm{S} 4$. It leads to lower $\mathrm{CO}_{2}$ emission as presented in Table 5. $\mathrm{CO}_{2}$ emission for S2 with the block paver $120 \mathrm{~mm}$ are 106,698 kton that is $18.41,21.88$, and 27.06 times higher than those of S1, S3, and S4, respectively, in the highway pavement. The lowest emission is for S4, however it needs thicker base layer in comparison with the other concrete base sections (S1 and S4). Therefore, the structural response of the concrete base for the highway pavement is equal, but their sustainable characteristics are different.

The same manner can be found in the port pavement section. Meanwhile, higher block thickness reduce fuel consumption, hence GHG emission, in the pavement construction. As an instance, $\mathrm{S} 4$ with $10 \mathrm{~cm}$ block requires $8.8 \times 10^{6} \mathrm{~m}^{3}$ fuel, $17.940 \mathrm{kton} \mathrm{CO}_{2}$, but the corresponding values are $8.6 \times 10^{7} \mathrm{~m}^{3}$ and $17.546 \mathrm{kton} \mathrm{CO}_{2}$ for the same section with $12 \mathrm{~cm}$ block.

In the other words, Figure 3 and Table 5 clearly show that $\mathrm{S} 2$ is significantly depend on the non-renewable natural resources, while S3 and S4 contains the by-product materials with higher strength, which resulted in thinner base. However, all the pavement section can withstand against 1,000,000 ESAL. So, structural response of the sections can be supposed equally. In contrast, their sustainable performance is different. As a result, an indicator is required to evaluate sustainability of the infrastructure assets with equal structural performance. To address this, the indicator is required to cover both structural and sustainability performances of a given assets. In this study, all the sections are able to withstand $1,000,000$ ESAL; hence it is selected as a structural parameter. Meanwhile, amount of $\mathrm{CO}_{2}$ emission is selected as parameter to measure sustainability.
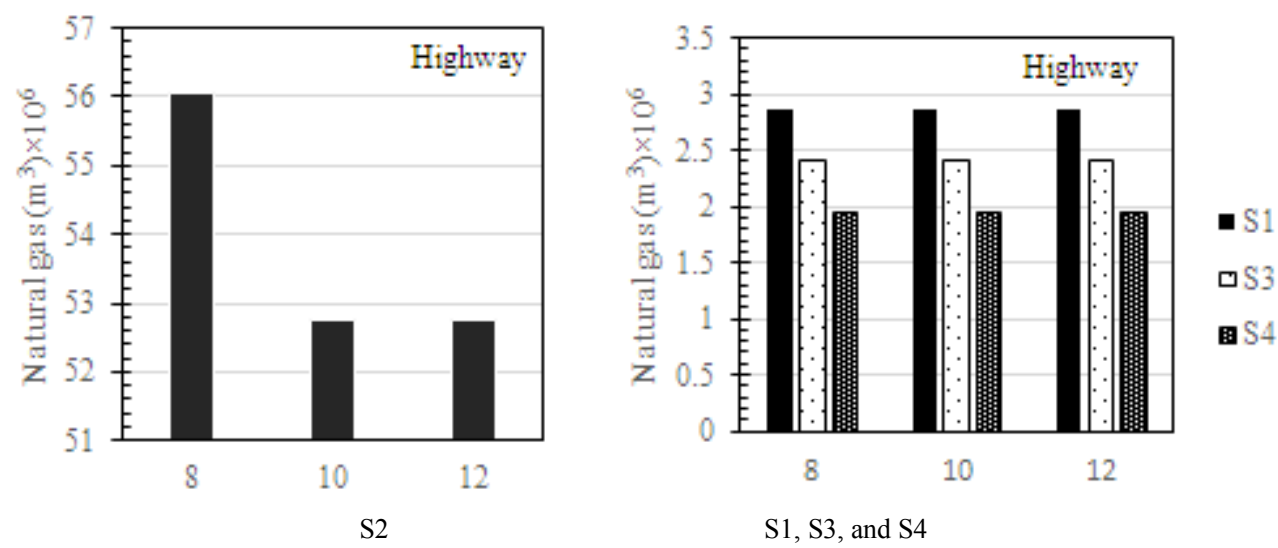

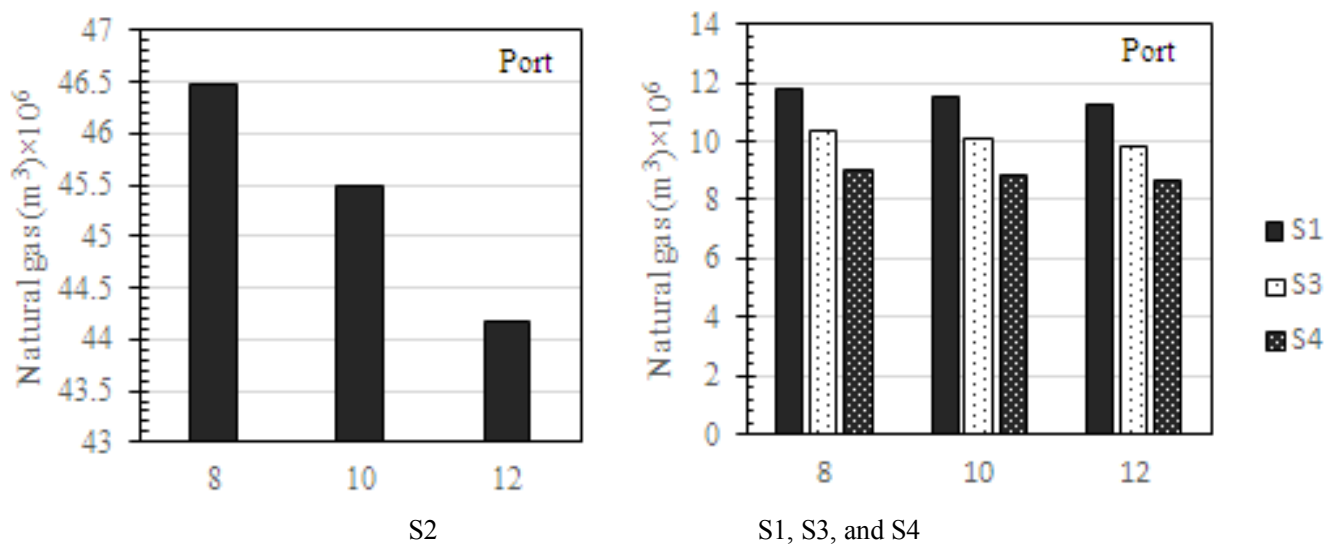

Figure 3. Fuel requirement for the pavement construction

Table 5. GHG emissions (kilo ton) for various sections for highway

\begin{tabular}{|c|c|c|c|}
\hline \multirow{2}{*}{ Section Code } & \multirow{2}{*}{$\begin{array}{l}\text { Block thickness } \\
\qquad(\mathrm{cm})\end{array}$} & Highway & Port \\
\hline & & $\mathrm{CO}_{2}$ & $\mathrm{CO}_{2}$ \\
\hline \multirow{3}{*}{$\mathrm{S} 1$} & 8 & 5801 & 23,871 \\
\hline & 10 & 5,793 & 23,267 \\
\hline & 12 & 5,793 & 22,694 \\
\hline \multirow{3}{*}{ S2 } & 8 & 113,366 & 94,003 \\
\hline & 10 & 106,698 & 92,003 \\
\hline & 12 & 106,698 & 89,336 \\
\hline \multirow{3}{*}{ S3 } & 8 & 4,882 & 20,994 \\
\hline & 10 & 4,874 & 20,474 \\
\hline & 12 & 4,874 & 19,987 \\
\hline \multirow{3}{*}{$\mathrm{S} 4$} & 8 & 3,950 & 18,370 \\
\hline & 10 & 3,942 & 17,940 \\
\hline & 12 & 3,942 & 17,546 \\
\hline
\end{tabular}

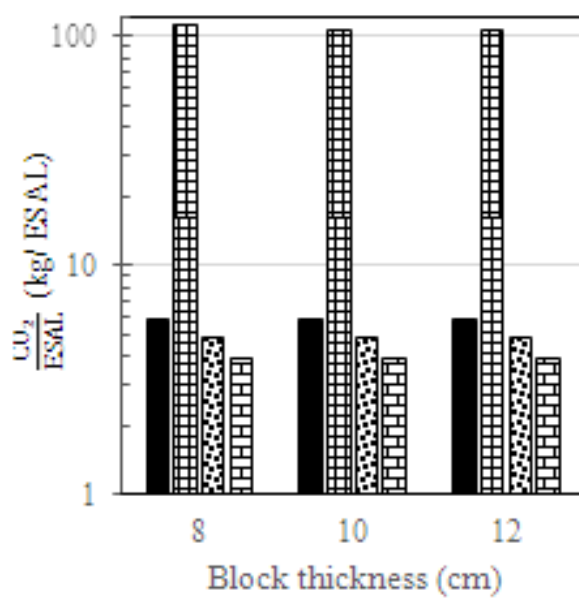

(a) for the highway

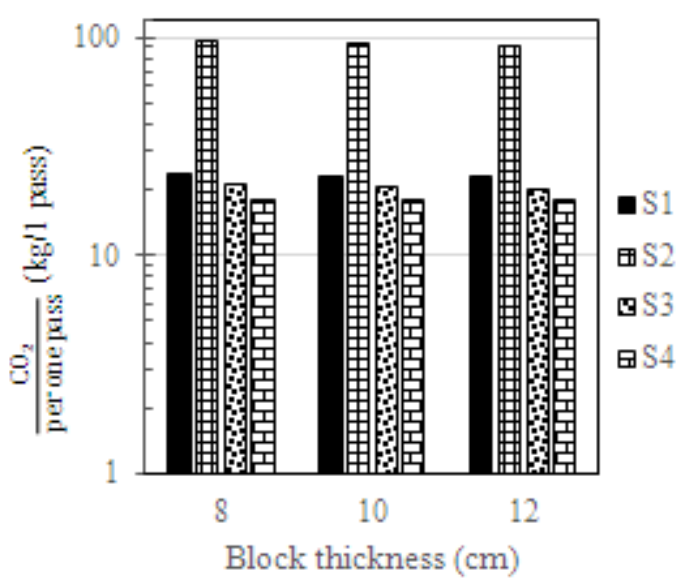

(b) for the port

Figure 4. $\frac{\mathrm{CO}_{2}}{\text { per traffic load }}$ ratios for various pavement sections

$\mathrm{CO}_{2}$ emission per ESAL is defined as a parameter that considers both structural response and sustainability. It means that amount of $\mathrm{CO}_{2}$ emission for design of the pavement that withstand for a given traffic loading $(1,000,000 \mathrm{ESAL}$ as traffic loading). When two highway pavement sections with various $\frac{\mathrm{CO}_{2}}{\mathrm{ESAL}}$ ratios are compared, the higher ratio means more $\mathrm{CO}_{2}$ are emitted to construct pavement that carries an equal traffic loading over the design life. Figure 4(a) shows $\frac{\mathrm{CO}_{2}}{\mathrm{ESAL}}$ ratios for the various highway pavement sections. It can be seen that $\frac{\mathrm{CO}_{2}}{\mathrm{ESAL}}$ ratios of S2 is significantly higher than those other pavement sections for both highway and port.

As an example, the ratio for S2 of highway pavement with $10 \mathrm{~cm}$ block is 106.69 that indicates $106.69 \mathrm{~kg} \mathrm{CO}_{2}$ is emitted for construction of a pavement to withstand 1 ESAL. In contrast, the corresponding ratio values for S1, $\mathrm{S} 3$, and $\mathrm{S} 4$ are $5.79,4.87$, and $3.94 \mathrm{~kg} \mathrm{CO}_{2}$ per $1 \mathrm{ESAL}$ (Figure 4 (a)). This indicator clearly shows that sustainability of S1, S2, and S3 are different, however, their structural performance are equal in term of required base thickness. Since the traffic loading is different, the indicator is defined per unit pass of the design vehicle. The indicator 
not only shows sustainable effect of FA in the pavement section for ports, but also characterizes the influence of the block thickness. Take S1 with $8 \mathrm{~cm}$ for the port pavement, $\mathrm{CO}_{2}$ emission for construction of a block pavement with a concrete base for 1 pass of straddle carrier is $23.84 \mathrm{~kg}$, while it is 22.69 for the same condition but with block 12 $\mathrm{cm}$.

\section{Conclusions}

Analysis of pavement sections showed that sustainability of pavement systems can be significantly different that depends on pavement application, material type, and amount of by-product material; however, their structural performance are equal. It means that the structural response of the concrete base incorporating the by-product materials, in terms of required thickness to withstand the traffic loading, is significantly depends on the pavement application. Moreover, the proposed indicator, showed that $\mathrm{CO}_{2}$ emissions of concrete base pavements per unit ESAL $\left(\frac{\mathrm{CO}_{2}}{\mathrm{ESAL}}\right)$ and unit pass of the design vehicle ( $\left.\frac{\mathrm{CO}_{2}}{1 \text { pass of the straddle carrier }}\right)$ were much lower than the pavements with asphalt bases, irrespective of the block paver thicknesses. Therefore concrete bases incorporating FA can be proposed as an alternative with high sustainability and structural performance for base layer of highways. $\frac{\mathrm{CO}_{2}}{\mathrm{ESAL}}$ or $\frac{\mathrm{CO}_{2}}{1 \text { Pass }}$ can be also used as an indicator to develop an integrated system not only consider structural properties, but also cover emissions in the pavement construction as one of most important infrastructure assets.

\section{Acknowledgements}

Many thanks are also due to the Sustainable Resources Division of Faculty of Engineering at the Hokkaido University. Also, the authors would like to acknowledge the Japan Society for the Promotion Science (JSPS) Fellows (grant number: 26.04058).

\section{REFERENCES}

[1] Uddin, W., Hudson, W.R., and Hass, R. (2013). Public Infrastructure Asset Management (second edition) McGraw-Hill Education, New York, United States. 2013.

[2] Zapata, P and Gambatese, J.A. Energy consumption of asphalt and reinforced concrete pavement materials and construction, J. Infra. Syst. ASCE, 11 (1), pp. 9-20. 2005.

[3] Häkkinen, T., and Mäkelä, K. Environmental adaptation of concrete; environmental impact of concrete and asphalt pavements. Technical Research Centre of Finland, Espoo, Finland.1996.

[4] Department for Environment, Food and Rural Affairs (DEFRA), Guidelines to GHGs calculation, Version 1.2.1. 2010 .

[5] Interlocking Concrete Pavement Institute (ICPI). Structural design of interlocking concrete pavements for roads and parking lots. Tech. Spec. 4, Interlocking Concrete Pavement Institute, Washington, DC, U.S.A.2003. 